\title{
Association of Depression with Sperm Quality: a Multicentre Cross-Sectional Study in China During the COVID-19 Pandemic
}

\section{Yongfeng Wang}

Huazhong University of Science and Technology Tongji Medical College

\section{Yuan Zhang}

Huazhong University of Science and Technology Tongji Medical College

\section{Yunyi Yang}

Huazhong University of Science and Technology Tongji Medical College

\section{Lihui Tu}

Peking University Institute of Mental Health: Peking University Sixth Hospital

\section{Jigao Yang}

Chongqing Popultion and Family Planning Science and Techology Research Institute

\section{Zhou Zhang}

Northwest Women and Children's Hospital

\section{Tianqing Meng}

Huaman Sperm Bank of Hubei Province

\section{Xianglong Jiang}

Traditional Chinese Medicine University of Jiangxi Province

\section{Wenbing Zhu}

Institute of Reproductive and Stem Cell Engineering,Basic Medicine Collage,Central South University,Changsha,Human,People's Republic of China

\section{Yushan Li}

Human Sperm Bank of Henan Province

\section{Huiping Zhang}

Huazhong University of Science and Technology Tongji Medical College

\section{Kai Zhao}

Huazhong University of Science and Technology Tongji Medical College

\section{Xinzong Zhang}

NHC Key Laboratory of Male Reproduction and Genetics

\section{Chunyan Liu ( $\sim$ lchy2019@hust.edu.cn )}

Huazhong University of Science and Technology Tongji Medical College https://orcid.org/0000-00022256-8954 
Research

Keywords: Depression, the COVID-19, semen concentration, semen volume, total sperm count, progressive motility.

Posted Date: July 13th, 2021

DOl: https://doi.org/10.21203/rs.3.rs-653536/v1

License: (c) (i) This work is licensed under a Creative Commons Attribution 4.0 International License.

Read Full License 


\section{Abstract}

Background: Depression is a potential factor affecting semen quality. However, the relationship between depression and semen quality remains to be fully elucidated. We investigated the association between depression and semen quality in men during the COVID-19 pandemic.

Methods: Cross-sectional, participants completed a questionnaire assessing lifestyle factors the Patient Health Questionnaire-9 (PHQ-9) was used to evaluate the psychological depression status of subjects. Semen quality assessment implements the requirements of the fifth edition of the World Health Organization (WHO )manual ,multivariable logistic regression analysis and linear regression analysis were conducted to assess the associations between depression and semen quality.

Results: Of the 896 participants, 173 were depressed (19.30\%). A Linear regression model was fitted to assess the strength and significant level of the association between depressive symptoms and semen quality. After adjusting for potential confounders, depression was significantly associated with 9.27 (95\% confidence interval [Cl] 3.39, 15.15), 0.57(95\% Cl 0.27, 0.87), 62.20 (95\% Cl 32.93, 91.48), and 12.96 (95\% $\mathrm{Cl} 10.55,15.37)$ reduction in sperm concentration, sperm volume, total sperm count, and progressive motility, respectively. Which are consistent with the logistic regression analysis results. The semen concentration and total sperm count were linearly correlated with depression scores, whereas the semen volume and progressive motility of sperm were nonlinearly correlated with depression scores.

Conclusions: Depression were associated with lower levels of semen concentration, semen volume, total sperm count, and progressive motility, which could affect male reproductive health.

\section{Plain Language Summary}

Depression may be associated with decreased semen quality. However, in the general population, there are limited studies on the effect of depressive symptoms on semen quality and the results are not clear. The purpose of this work is to explore the association between depressive symptoms and semen quality during the COVID-19 pandemic .

A cross sectional study design was employed. A questionnaire survey was conducted during the COVID19 pandemic among sperm donor who visited 7 sperm banks in China, a total of 896 valid questionnaires were collected. the Patient Health Questionnaire-9 (PHQ-9) was used to assess depressive symptoms, the depression rate was $19.30 \%$. Semen quality assessment implements the requirements of the fifth edition of the World Health Organization (WHO )manual. multivariable logistic regression analysis and linear regression analysis were conducted to assess the associations between depression and semen quality. The linear regression results of adjusting for potential confounders show that depression was significantly associated with a 9.27 (95\% confidence interval $[\mathrm{Cl}] 3.39,15.15), 0.57(95 \% \mathrm{Cl} 0.27,0.87)$, $62.20(95 \% \mathrm{Cl} 32.93,91.48)$, and $12.96(95 \% \mathrm{Cl} 10.55,15.37)$ reduction in sperm concentration, sperm volume, total sperm count, and progressive motility, respectively. Which are consistent with the logistic regression analysis results. The semen concentration and total sperm count were linearly correlated with 
depression scores, whereas the semen volume and progressive motility of sperm were nonlinearly correlated with depression scores. Hence, depression were associated with lower levels of semen concentration, semen volume, total sperm count, and progressive motility, which could affect male reproductive health. Pay attention to the psychological changes of men of childbearing age, and promptly guide the mental depression of men of childbearing age, which may have certain clinical significance for maintaining the quality of male semen.

\section{Introduction}

Infertility affects approximately $15 \%$ of couples worldwide, and male causes account for about $50 \%$ [1]. The 'China Infertility Current Situation Research Report' released by the China Population Association, indicated that the infertility rate of China's childbearing age population is $15-20 \%$, and the number of infertile couples reached 20 million. A large number of studies have shown that about $30 \%$ of infertility cases are due to male factors ${ }^{[3]}$. Poor semen quality is believed to be a major cause of male infertility [2]. A recent meta-analysis of Western population data from 1973 to 2011 showed that semen quality in Western males has declined by $50 \%[3]$, and a growing number of studies have reported that male semen quality around the world is declining [4].

Smoking, excessive drinking, Body Mass Index( BMI), adverse psychological state, and other factors may be responsible for the decline of semen quality. Few studies have reported on psychological depression and male semen quality, but it is difficult to reach a unified conclusion due to the diversity of study population, study design, and analysis methods. The results of published studies have mainly focused on infertile or subfertile men. For example, an analysis of semen samples from 112 Swiss men with low fertility found that depression is associated with lower semen quality[5]. In a prospective, multi-center clinical trial, a study of semen samples from 809 infertile men discovered that depression is negatively associated with testosterone secretion levels [6]. At present, few studies have investigated the association between depressive symptoms and semen quality in the general Chinese population. A recent single center study on Chinese college students showed that, depressive symptoms may be associated with decreased semen concentration and total sperm count [7]. However, the conclusion of this study cannot represent the majority of Chinese men, because the study population is limited to college students and belongs to a single-center study design.

The COVID-19 epidemic has become a major public health event affecting people's health. Public health emergencies are known to have adverse effects on individual health (e.g., insecurity, confusion, emotional isolation, and stigma) and communities (owing to economic loss, work and school closures, inadequate resources for medical response)[8-10]. These phenomena may translate into a range of emotional reactions, such as anxiety, depression, and other adverse psychological symptoms [11]. During the COVID-19 pandemic, higher rates of depressive symptoms were detected among healthcare workers, adolescents, college students, general population, and pregnant women than during the non-pandemic period [12-16]. Research reports show that depression not only causes pain to patients, but also leads to poor sleep quality, loss of appetite, fatigue, symptoms of autonomic nervous dysfunction, and other 
adverse effects $[17,18]$. Reports concerning the effects of depression on male reproduction are limited. In addition, similar studies on major health events have not been reported. The present study was designed to investigate the relationship between depressive symptoms and semen quality in men during the COVID-19 pandemic, and to provide some epidemiological evidence for the etiology of male reproduction research.

Taken together, the current research evidence on the association between depressive symptoms and semen quality is limited, and further research is required. In this research, we conducted a large-scale observational study on 896 healthy sperm donors from several sperm banks in China during the COVID19 and performed dose-response analysis to quantitatively evaluate the relationship between depressive symptoms and semen quality.

\section{Materials And Methods}

\subsection{Design and participants}

This study is a multicenter cross-sectional study conducted during the COVID-19. A total of 1236 questionnaires were retrieved from seven sperm banks in China. After screening according to the inclusion and exclusion criteria, 896 qualified questionnaires were finally obtained. The exclusion criteria were as follows: patients with genital tract disease, genetic disease diagnosis or family genetic disease, and infectious diseases; patients who are pathogen carriers; patients with hypertension, diabetes, and mental illness; and patients who lack semen quality reports. The inclusion criteria were as follows: age 18 to 42 years old, no history of mental illness, and no history of drug and organic disease in the last 3 months. The details of the study design and analysis of related processes are shown in Fig. 1. The study was approved by the Association of Ethical Review of Tongji Medical College, Huazhong University of Science and Technology. All participants completed questionnaires, including demographic characteristics, living habits, and psychological depression, and signed an informed consent. The semen concentration, semen volume, total sperm count, and forward motility were used as outcome indicators.

\subsection{Depressive Symptoms}

\section{Patient Health Questionnaire}

In this study, the Patient Health Questionnaire was used to evaluate the psychological depression status of subjects [19]. The scale consists of nine items, which belong to the criteria of major depression in the Diagnostic and Statistical Manual of Mental Disorders. This scale has high sensitivity and has been widely used in the adult population. Each item was scored on a scale of $0-3$. Participants completed a mental scale assessment based on their psychological feelings according to their mental state in the last two weeks while completing the semen collection. On the basis of previous studies, a score of 5-9 was defined as mild depression, and a score of 10 or greater was defined as severe depressive symptoms [20, 21]. The reliability and validity of the simplified Chinese version of PHQ-9 have been demonstrated [22].

\subsection{Semen Sample Collection And Analysis}


The semen of each eligible subject was collected for routine semen analysis according to the inclusion criteria of the questionnaire survey, and the participants provided semen samples via masturbation in the sperm collection room. At the same time, the participant's abstinence time and time of ejaculation were recorded. According to the latest guidelines of the World Health Organization, the semen concentration, semen volume, total number of sperm, and forward motility of sperm were detected and recorded for subsequent statistical analysis [23]. Immediately after ejaculation, the sample was collected and placed in an incubator at $37^{\circ} \mathrm{C}$ for incubation. The liquefaction time $(<1 \mathrm{~h})$ was recorded. This step was completed within $1 \mathrm{~h}$. The color of semen was observed and recorded, and the semen volume was estimated by weighing method $(1 \mathrm{~g}=1 \mathrm{~mL})$. About $10 \mu \mathrm{L}$ of semen was taken for smear to observe the morphology of sperm. The procedure was carried out in strict accordance with the latest WHO guidelines [24]. A computer-aided sperm analysis system (SCA CASA System, MicroChip S.L., Barcelona, Spain) was used to assist in the analysis of semen concentration and sperm motility indicators. In order to reduce errors caused by human manipulation, a skilled technician was selected for each sperm bank to perform the process in strict accordance with the implementation specifications.

The normal ranges for semen volume, total sperm count, semen concentration, and progressive motility were assessed strictly in accordance with the WHO fifth edition manual [25].

\subsection{Statistical analysis}

Classification variables in the data were presented in the form of frequency and percentage, while continuous variables were represented as mean \pm standard deviation. The respondents were divided into depressed group and non-depressed group according to the scoring principle of PHQ-9. The scoring rules are described in the methods section. Table 1 describes the basic characteristics of the studying population, including weight, BMl, age, educational level, smoking, drinking, and other factors. Table 2 compares the differences in semen parameters (including semen concentration, total sperm count, semen volume, and progressive motility of sperm) between the two groups.

To verify the stability of the results, multivariate linear regression analysis and logistic regression analysis were used to examine the association between depression and sperm concentration, semen volume, total sperm count, and progressive motility. The odds ratio (OR) and $95 \%$ confidence interval $(95 \% \mathrm{Cl})$ were calculated, and the distribution of depression scale scores was significantly skewed to the right. Logarithmic transformation was performed before multiple linear regression analysis, and the estimates were reconstructed using exponential formulas [26-29].

To analyze the relationship between depression grade and semen quality, logistic regression model was used after converting the sperm concentration, semen volume, total sperm count, and progressive motility from continuous variable data to binary variables. The "WHO Human Semen Inspection and Processing Laboratory Manual" (fifth edition) was used to determine whether the indicators are qualified or not [7]. The values of semen quality indicators were directly incorporated into the linear regression model as continuous variable data, and depression symptoms were incorporated into the model as dichotomous variable data [30]. The model were adjusted for latent variables known to have an impact on semen 
quality (smoking[26], drinking[31], BMI[32] ). When analyzing the association between depression and four outcome variables of semen quality, several indexes influencing semen quality reported by previous studies, including smoking, drinking and $\mathrm{BMI}$, were set as fixed adjustment variables. Other covariables were filtered according to the screening principle of published articles. We selected these confounders on the basis of their associations with the outcomes of interest or a change of more than $10 \%$ in effect estimate $[33,34]$. Supplementary Tables S1-S4 show the associations of each confounder with the outcomes of interest. The regression analysis results are shown in Tables 3 and 4.

The depression scale scores of all participants were divided into three categories according to the grading standard. Participants with scores between 0 and 4 were considered to have no depressive symptoms, those with scores between 5 and 9 were considered to be mildly depressed, and those with scores over 10 were considered to be severely depressed. The Cochran-Armitage trend test was used to determine whether there was a certain trend between depressive symptom grade and semen quality, as shown in Table 5. Curve fitting was used to test whether there was a linear relationship between the trend of depressive symptom score and various parameters of semen quality. The dose-response curve of each index is shown in Figs. 2-5. Meanwhile, the variables of each parameter index were adjusted according to the covariate screening principle. A two-stage linear regression model was used to test the threshold effect of depression score on semen quality by smoothing function.

For all analyses, the percentage of covariate's missing values was less than $20 \%$. We used multiple estimations to calculate the missing data of covariates, and used multiple regression algorithm to process the covariant data [35]. $P$-values $<0.05$ were interpreted as statistically significant. All statistical analyses were performed using EmpowerStats (http://www.empowerstats .com) and the statistical package $\mathrm{R}(4.03$ version).

\section{Results}

\subsection{Participant Characteristics}

Of the 896 participants, 173 were depressed (19.30\%).The characteristics of the study participants are shown in Table 1. Depressed participants had higher BMI $(P=0.020)$ than non-depressed participants. Differences were observed in smoking, time using electronics, and sedentary time between depressed and non-depressed participants $(P<0.05)$. 
Table 1

Characteristics of the study subjects by depression category.

\begin{tabular}{|c|c|c|c|}
\hline Depression & Non-depressed & Depressed & P-value \\
\hline$N$ & 723 & 173 & \\
\hline Weight(Kg) & $68.72 \pm 10.14$ & $67.27 \pm 10.49$ & 0.061 \\
\hline BMI & $22.64 \pm 3.15$ & $22.07 \pm 3.09$ & 0.020 \\
\hline Age & $25.76 \pm 4.89$ & $24.97 \pm 4.60$ & 0.040 \\
\hline smoking & & & 0.001 \\
\hline NO & $203(28.08)$ & $70(40.46)$ & \\
\hline YES & $520(71.92)$ & $103(59.54)$ & \\
\hline Drinking & & & 0.197 \\
\hline NO & $629(87.00)$ & $144(83.24)$ & \\
\hline YES & $94(13.00)$ & $29(16.76)$ & \\
\hline Education Level & & & 0.591 \\
\hline Under high school & $150(20.75)$ & $43(24.86)$ & \\
\hline Junior college & $278(38.45)$ & $67(38.73)$ & \\
\hline Undergraduate and higher & $292(40.39)$ & $62(35.84)$ & \\
\hline Time spent using electronics & & & $<0.001$ \\
\hline Less than $6 \mathrm{~h}$ & $586(81.05)$ & $116(67.05)$ & \\
\hline More than $6 \mathrm{~h}$ & $137(18.95)$ & $57(32.95)$ & \\
\hline Sedentary time (days) & & & 0.031 \\
\hline Less than $6 \mathrm{~h}$ & $573(79.25)$ & $124(71.68)$ & \\
\hline More than $6 \mathrm{~h}$ & $150(20.75)$ & $49(28.32)$ & \\
\hline Marriage & & & 0.483 \\
\hline Unmarried & $616(85.20)$ & $151(87.28)$ & \\
\hline Married & $107(14.80)$ & $22(12.72)$ & \\
\hline Debt pressure & & & 0.459 \\
\hline
\end{tabular}

Results in the table: Mean $+\mathrm{SD} / \mathrm{N}(\%)$

$P$ value *: For continuous variables, Kruskal Wallis rank sum test was used. For counting variables with theoretical number $<10$, Fisher exact probability test was used. This table with YIER statistical software (www.empowerstats.com) and R software generated, generate date: 2020-11-15 


\begin{tabular}{|c|c|c|c|}
\hline Depression & Non-depressed & Depressed & P-value \\
\hline Yes & 316 (43.71) & $81(46.82)$ & \\
\hline No & 407 (56.29) & $92(53.18)$ & \\
\hline \multicolumn{4}{|c|}{$\begin{array}{l}\text { Results in the table: Mean }+\mathrm{SD} / \mathrm{N}(\%) \\
\mathrm{P} \text { value } * \text { : For continuous variables, Kruskal Wallis rank sum test was used. For counting variables } \\
\text { with theoretical number < } 10 \text {, Fisher exact probability test was used. This table with YIER statistical } \\
\text { software (www.empowerstats.com) and R software generated, generate date: } 2020-11-15\end{array}$} \\
\hline
\end{tabular}

\subsection{The distribution of semen parameters in depression and non-depression subjects}

The semen indicators (progressive motility, semen concentration, semen volume, and total sperm count) of depressed participants were lower than those of non-depressed participants (51.21 $\pm 12.23 \mathrm{vs}$. $38.31 \pm$ $16.60[\%], 57.40 \pm 32.78$ vs. $45.76 \pm 29.96\left[10^{6} / \mathrm{mL}\right], 3.66 \pm 1.67$ vs. $3.03 \pm 1.68[\mathrm{~mL}]$, and $212.85 \pm 164.03$ vs. $141.97 \pm 125.10\left[10^{6}\right]$, respectively). A statistical difference was observed in the semen quality between the two groups $(P<0.05)$ (sperm concentration, semen volume, total sperm count, and progressive motility were considered as qualified semen sample; otherwise, unqualified semen sample). The abstinence time did not differ between the two groups (Table 2).

Table 2

Distribution of semen quality parameters by depression status category.

\begin{tabular}{|c|c|c|c|}
\hline \multirow[t]{2}{*}{ Parameter } & \multicolumn{2}{|l|}{ Depression } & \multirow[t]{2}{*}{$P$-value } \\
\hline & Non-depressed $(n=723)$ & Depressed $(n=173)$ & \\
\hline Progressive motility & $38.31 \pm 16.60$ & $51.21 \pm 12.23$ & $<0.001 *$ \\
\hline Semen concentration & $45.76 \pm 29.96$ & $57.40 \pm 32.78$ & $<0.001 *$ \\
\hline Semen volume & $3.03 \pm 1.68$ & $3.66 \pm 1.67$ & $<0.001^{*}$ \\
\hline Total sperm count & $141.97 \pm 125.10$ & $212.85 \pm 164.03$ & $<0.001 *$ \\
\hline Abstinence time & $5.15 \pm 2.49$ & $5.37 \pm 3.18$ & 0.514 * \\
\hline Semen quality & & & $<0.001$ \\
\hline Below standard & $680(94.05)$ & $38(21.97)$ & \\
\hline Up to standard & $43(5.95)$ & $135(78.03)$ & \\
\hline \multicolumn{4}{|c|}{$\begin{array}{l}\text { Results in the table: Mean }+\mathrm{SD} / \mathrm{N}(\%) \\
\mathrm{P} \text { value } * \text { : For continuous variables, Kruskal Wallis rank sum test was used. For counting variables } \\
\text { with theoretical number < } 10 \text {, Fisher exact probability test was used. This table with YIER statistical } \\
\text { software (www.empowerstats.com) and R software generated, generate date: } 2020-11-15\end{array}$} \\
\hline
\end{tabular}

\subsection{Logistic regression analysis of depression and semen parameters}


The results of logistic regression analysis showed that, depression group had $7.97(95 \% \mathrm{Cl} 4.10,15.49)$ lower sperm concentration, $9.23(95 \% \mathrm{Cl} 5.06,16.86)$ lower sperm volume, $4.90(95 \% \mathrm{Cl} 3.01,7.99)$ lower total sperm count, and $23.65(95 \% \mathrm{Cl} 14.82,37.74)$ lower progressive motility than without depression group. After adjusting the variables according to the adjustment strategy, depression group had 12.62 (95\% Cl: $5.77,27.61)$ lower sperm concentration, $10.10(95 \% \mathrm{Cl} 4.99,20.45)$ lower sperm volume, and 6.62(95\% Cl: $3.70,11.83)$ lower total sperm count and $30.47(95 \% \mathrm{Cl}: 17.23,53.88)$ lower progressive motility than without depression group(Table 3).

Table 3

Correlation analysis of depression and semen parameters (Logistics regression analysis)

\begin{tabular}{|c|c|c|c|c|}
\hline Characteristic & Model & depression & $\mathrm{OR}(95 \% \mathrm{Cl})$ & $P$-value \\
\hline \multirow[t]{4}{*}{ Sperm concentration } & \multirow[t]{2}{*}{ Crude } & NO & Reference & $<0.001$ \\
\hline & & YES & $7.97(4.10,15.49)$ & \\
\hline & \multirow[t]{2}{*}{ Adjusted $^{\mathrm{b}}$} & NO & Reference & 0.021 \\
\hline & & YES & $12.62(5.77,27.61)$ & \\
\hline \multirow[t]{4}{*}{ Semen volume } & Crude & NO & Reference & $<0.001$ \\
\hline & & YES & $9.23(5.06,16.86)$ & \\
\hline & Adjusted $^{\mathrm{b}}$ & NO & Reference & 0.002 \\
\hline & & YES & $10.10(4.99,20.45)$ & \\
\hline \multirow[t]{4}{*}{ Total sperm count } & Crude & NO & Reference & $<0.001$ \\
\hline & & YES & $4.90(3.01,7.99)$ & \\
\hline & Adjusted $^{b}$ & NO & Reference & $<0.001$ \\
\hline & & YES & $6.62(3.70,11.83)$ & \\
\hline \multirow[t]{4}{*}{ Progressive motility } & Crude & NO & Reference & $<0.001$ \\
\hline & & YES & $23.65(14.82,37.74)$ & \\
\hline & Adjusted $^{b}$ & NO & Reference & $<0.001$ \\
\hline & & YES & $30.47(17.23,53.88)$ & \\
\hline \multicolumn{5}{|c|}{ The results in bold indicate that the results were statistically significant. $(p<0.05)$} \\
\hline \multicolumn{5}{|c|}{$\begin{array}{l}\text { Cl: Confidence interval, confidence interval. b. The regression equation has been adjusted for age, } \\
\text { BMI, worry about being infected with the new crown, smoking, drinking, occupation and education } \\
\text { level. This table with YlER statistical software (www.empowerstats.com) and R software generated, } \\
\text { generate date: } 2020-11-17\end{array}$} \\
\hline
\end{tabular}


The results of linear regression analysis were similar to those of logistic regression analysis. Compared with non-depression group, sperm concentration decreased by 11.6 (95\% Cl 6.28, 16.98), semen volume decreased by 0.63 (95\% Cl: $0.91,0.36)$, total sperm count decreased by $70.88(95 \% \mathrm{Cl}: 44.78,96.97)$, and progressive motility decreased by $12.91(95 \% \mathrm{Cl}: 10.72,15.10)$. After adjusting for the covariates of each outcome measure according to the screening principle, compared with non-depression group, sperm concentration decreased by 9.27 ( $95 \% \mathrm{Cl}$ : $3.39,15.15)$, semen volume decreased by 0.57 ( $95 \% \mathrm{Cl}$ : 0.27 , $0.87)$, total sperm count decreased by 62.20 (95\% Cl: $32.93,91.48)$, and progressive motility decreased by 12.96(95\% Cl: 10.55, 15.37), respectively(Table 4).

Table 4

Correlation analysis of depression and semen parameters (Linear regression analysis)

\begin{tabular}{|c|c|c|c|c|}
\hline Characteristic & Model & depression & $\beta(95 \% \mathrm{Cl})$ & $P$-value \\
\hline \multirow{4}{*}{$\begin{array}{l}\text { Sperm concentration } \\
\left(\times 10^{6} \mathrm{~mL}\right)\end{array}$} & \multirow[t]{2}{*}{ Crude } & NO & Reference & $<0.001$ \\
\hline & & YES & $-11.63(-16.98,-6.28)$ & \\
\hline & \multirow[t]{2}{*}{ Adjusted $^{\mathrm{b}}$} & NO & Reference & 0.021 \\
\hline & & YES & $-9.27(-15.15,-3.39)$ & \\
\hline \multirow[t]{4}{*}{ Semen volume $(\mathrm{mL})$} & Crude & NO & Reference & $<0.001$ \\
\hline & & YES & $-0.63(-0.91,-0.36)$ & \\
\hline & Adjusted $^{b}$ & NO & Reference & 0.002 \\
\hline & & YES & $-0.57(-0.87,-0.27)$ & \\
\hline \multirow{4}{*}{$\begin{array}{l}\text { Total sperm count } \\
\left(\times 10^{6}\right)\end{array}$} & Crude & NO & Reference & $<0.001$ \\
\hline & & YES & $-0.63(-0.91,-0.36)$ & \\
\hline & Adjusted $^{\mathrm{b}}$ & NO & Reference & $<0.001$ \\
\hline & & YES & $-62.20(-91.48,-32.93)$ & \\
\hline \multirow[t]{4}{*}{ Progressive motility(\%) } & Crude & NO & Reference & $<0.001$ \\
\hline & & YES & $-70.88(-96.97,-44.78)$ & \\
\hline & Adjusted $^{b}$ & NO & Reference & $<0.001$ \\
\hline & & YES & $-12.96(-15.37,-10.55)$ & \\
\hline \multicolumn{5}{|c|}{ The results in bold indicate that the results were statistically significant. $(p<0.05)$} \\
\hline \multicolumn{5}{|c|}{$\begin{array}{l}\text { Cl: Confidence interval, confidence interval. b. The regression equation has been adjusted for age, } \\
\text { BMI, worry about being infected with the new crown, smoking, drinking, occupation and education } \\
\text { level. This table with YIER statistical software (www.empowerstats.com) and R software generated, } \\
\text { generate date: } 2020-11-17\end{array}$} \\
\hline
\end{tabular}




\subsection{Association of depression score level and semen quality parameters}

After adjusting for confounding factors(Table S1), the depressive symptoms were diveded into three categories according to the classification criteria of the depression score scale, which are normal mentality ( $\leq 4$ points), mild depression (5-9), and severe depression $(\geq 10)$. The trend test results of the relationship between depression level and semen quality show that as the severity of depressive symptoms increases, semen parameters gradually decrease, and the trend is significant $(P$ for trend < 0.05)( Table 5).

Table 5

Trend test of semen quality parameters classified by depression grade

\begin{tabular}{|c|c|c|c|c|c|}
\hline Indicators & & $\mathbf{N}$ & \%events & $\mathrm{OR}(95 \% \mathrm{Cl})$ & $P$ for trenc \\
\hline \multirow[t]{3}{*}{ Progressive motility } & Normal & 723 & 80.69 & $51.19(50.22,52.16)$ & $<0.001$ \\
\hline & Mild & 133 & 14.84 & $38.84(36.55,41.13)$ & \\
\hline & Severe & 40 & 4.46 & $36.96(32.77,41.16)$ & \\
\hline \multirow[t]{3}{*}{ Sperm count } & Normal & 723 & 80.69 & $211.24(199.82,222.67)$ & $<0.001$ \\
\hline & Mild & 133 & 14.84 & $158.88(131.94,185.83)$ & \\
\hline & Severe & 40 & 4.46 & $114.78(65.36,164.19)$ & \\
\hline \multirow[t]{3}{*}{ Semen concentration } & Normal & 723 & 80.69 & $57.04(54.72,59.35)$ & $<0.001$ \\
\hline & Mild & 133 & 14.84 & $50.80(45.34,56.26)$ & \\
\hline & Severe & 40 & 4.46 & $35.51(25.49,45.52)$ & \\
\hline \multirow[t]{3}{*}{ Semen volume } & Normal & 723 & 80.69 & $3.65(3.53,3.77)$ & $<0.001$ \\
\hline & Mild & 133 & 14.84 & $3.09(2.80,3.38)$ & \\
\hline & Severe & 40 & 4.46 & $3.02(2.50,3.55)$ & \\
\hline \multicolumn{6}{|c|}{ Results in the table: Mean + SD/N(\%) } \\
\hline \multicolumn{6}{|c|}{$\begin{array}{l}\text { P value *: For continuous variables, Kruskal Wallis rank sum test was used. For counting variables } \\
\text { with theoretical number }<10 \text {, Fisher exact probability test was used. This table with YIER statistical } \\
\text { software (www.empowerstats.com) and R software generated, generate date: } 2020-11-15 \text {. }\end{array}$} \\
\hline
\end{tabular}

The association with semen quality parameters and depression scores was evaluated, which showed a linear downward trend of semen concentration and total sperm count with the estimated dose-response curves of depression scores (Fig S2 and Fig S3). However, a nonlinear relationship was observed between semen volume, sperm progressive motility, and depression score(Fig. 2 and Fig. 3). The threshold effect of depression score on semen volume and progressive motility was analyzed using piecewise linear 
regression. The semen volume decreased as the depression score increased until the turning point (PHQ $>8$ ), with a correlation coefficient (OR) was -0.1 (95\% Cl, $-0.1-0.1)$ ( Fig. 2, Table 6). The estimated doseresponse curve was horizontal in the $\mathrm{PHQ}>8$ score range, no significant correlation was observed between the depression score and the semen volume $(P<0.05)$,(Fig. 2, Table 6).

Table 6

Threshold effect analysis of scores on semen volume using piece-wise linear regression

\begin{tabular}{|lll|}
\hline Depression scores & OR(95\% Cl) & $P$ Value \\
\hline Scores & $-1.33(-1.57,-1.09)$ & $<0.0001$ \\
\hline Inflection point & 8 & \\
\hline Scores $<8$ & $-1.63(-1.98,-1.28)$ & $<0.0001$ \\
\hline Scores $\geq 8$ & $-0.00(-1.29,0.08)$ & 0.0843 \\
\hline \multicolumn{2}{|l}{ a Adjusted for somking, drinking, BMI, age } \\
\hline
\end{tabular}

Similarly, the progressive motility decreased with increasing depression score until the turning point (PHQ $<8)$. The correlation coefficient (OR) was $-1.63(95 \% \mathrm{Cl},-1.98-1.28, P<0.005)$. However, in the $\mathrm{PHQ}>8$ scoring range, the estimated dose-response curve was horizontal, no significant correlation was observed between the depression score and the semen volume $(P<0.05)$, ( Fig. 3, Table 7).

Table 7

Threshold effect analysis of scores on progressive motility using piece-wise linear regression

\begin{tabular}{|lll|}
\hline Depression scores & OR(95\% Cl) & $P$ Value \\
\hline Scores & $-0.1(-0.1,-0.1)$ & $<0.001$ \\
\hline Inflection point & 8 & \\
\hline Scores $<8$ & $-0.1(-0.1,-0.1)$ & $<0.001$ \\
\hline Scores $\geq 8$ & $0.0(-0.1,0.1)$ & 0.932 \\
\hline a Adjusted for somking, drinking, BMI, age \\
\hline
\end{tabular}

\section{Discussion}


The results of this study, which included 896 participants, showed a negative association between depression and semen parameters (semen concentration, semen volume, total sperm count, and progressive motility of sperm) in men, and a nonlinear decrease in depression with semen volume and progressive motility of sperm.

The results of this study are consistent with a previous research [7, 31], showing that depression may be associated with decreased semen volume and sperm concentration. Similarly, in another study involving 70 infertile men, psychological stress may be negatively associated with total serum testosterone levels and semen quality [36]. A single-center cross-sectional study of 587 college students in China also found that depression in men is associated with poor semen quality, including a decrease in semen concentration and quantity [7]. Consistent with this study, our results also showed that there is a negative association between depression and semen quality.

In the study population, we further revealed a potential link between the depression threshold effect and semen quality. To our knowledge, this is the first epidemiological study to provide clear evidence of a nonlinear and potential association between depression score levels and progressive motility of sperm. In a prospective cohort study on psychological stress and semen quality, poor semen quality was detected in a dose-responsive manner among men with self-reported stress scores above moderate stress levels [37]. The trend test of this study also showed that all indexes of semen parameters decreased with increasing depression grade. A quantitative dependence was observed between depression and semen parameters (semen concentration, semen volume, total sperm count, and progressive motility). Threshold test and piecewise linear function of depression and semen volume showed that, semen volume decreases with increasing depression grade when the grade is less than 8 , and doesn't change with depression grade when the grade is grater than 8 . The threshold test results of the study population showed that the mean semen volume ranged from $1.5 \mathrm{~mL}$ to $4.0 \mathrm{~mL}$. A study based on the World Health Organization's fifth edition of the Laboratory Manual for the Examination and Treatment of Human Semen recommends a normal range of 1.5 to $6 \mathrm{~mL}$ for male semen volume [38]. Hence,in the present study, the semen volume decreased as the depression scores increased, but the changes were within the recommended normal range. Similarly, Threshold test and piecewise linear function of depression and semen progressive motility showed that, progressive motility decreases with increasing depression grade $\llbracket$ which accord with recent studies [4, 39-41]. Progressive motility decreases significantly when depression grade is less than $8(p<0.05)$, decreases insignificantly when depression grade is grater than $8(p<0.05)$, and has fallen to reference value $(32-72 \%)$ when depression grade equals 8 .

A retrospective cross-sectional study of 71,623 infertile men in China from 2011 to 2017 found no evidence of deteriorating semen quality in infertile men in Hunan, China. However, sperm motility is a necessary indicator of Assisted Reproductive Technology (ART) fertility [42].

According to the molecular mechanism analysis, neuroendocrine dysfunction may be associated with the effect of depression on semen quality [43]. Some researchers have proposed that the molecular mechanism of depression may be related to stress-related cortisol release and impaired feedback 
inhibition mediated by glucocorticoid receptors $[44,45]$. In vitro experiments have shown that glucocorticoids induce apoptosis or senescence in Leydig cells, and induce apoptosis $[46,47]$ in early spermatogenic cells (spermatogonia and pachytene spermatocytes). However, these research data came from animal experiments or in vitro experiments, and have not been confirmed in population survey studies.

Studies on the relationship between depression and semen quality are limited. However, multiple researches have shown that major public health events can increase the risk of depression. This study investigated male during the COVID-19 pandemic, and thus may be of great significance for preventing the decline of semen quality in 18-42-year-old individuals when major public health events occur, and may also provide certain reference value for exploring the etiology of male infertility.

\section{Conclusions}

Depressive symptoms were associated with lower levels of semen concentration, semen volume, total sperm count, and progressive motility, which could affect male reproductive health. Our research shows that paying attention to the psychological depressive symptoms of males of childbearing age during major public health events may be of great significance in preventing the deterioration of semen quality.

The advantages of our study are as follows: first, the population in our study is special. Obtaining similar research data of men during the epidemic period is difficult. Second, to date, this study is the first to use a threshold test to analyze the relationship between depression and semen quality. Third, in addition to the questionnaire, we also obtained semen test results of each study subject, which has not been reported in this kind of research during the epidemic period. The limitations of our study are as follows: first, the age range of subjects included in this study was between 18 and 42 years. Thus, the results are not applicable to all men. Second, the study was conducted after the outbreak of the epidemic, so comparative data before the epidemic are lacking. Third, the questionnaire used in this study was completed by online filling, without face-to-face conversation.

\section{Abbreviations}

PHQ-9: the Patient Health Questionnaire; WHO: the World Health Organization;

Cl: confidence interval; BMI: Body Mass Index; OR: odds ratio; ART: Assisted Reproductive Technology.

\section{Declarations}

\section{Ethics approval and consent to participate}

The study has been approved by the Ethics Committee of Tongji Medical College, Huazhong University of Science and Technology. During data collection, the study participants were consulted and agreement on consent forms was signed. 


\section{Consent for publication}

Not Applicable.

\section{Availability of data and materials}

The dataset that supports the findings of this study is available from the corresponding author upon reasonable request.

\section{Competing interests}

The authors have stated explicitly that there are no conflicts of interest in connection with this article.

\section{Funding}

This research project was funded by the National Key R\&D Program of China (2018YFC1004300, 2018YFC1004304); Chongqing Research Institute performance incentive and guidance project (cstc2018jxj I120004); Guangzhou science and Technology Project(202002030480); Guangdong Medical Research Fund (A2019336) ;Guangzhou science and Technology Project (201707010394)

\section{Authors' contribution}

All authors participated in the research. Z.Y., F.Y. and Z.K. designed the study, Z.Y. and Z.H. participated in data collection and collation, Y.Y, L.C and T.L. revised the article. W.Y. collated data, analysis, summarized the results and drafted the article.Y.J.,Z.Z.,M.T.,J.X.,Z.W.,L.Y. and Z.X. collected the clinical data. All authors read and approved the final manuscript.

\section{Acknowledgements}

We thank the Guangdong Sperm Bank, Chongqing Sperm Bank, Henan Sperm Bank, Hubei Sperm Bank and Hunan Sperm Bank, who assisted with collecting the questionnaire, and we thank all subjects for participating in our study.

\section{References}

1. Vickram AS, Samad HA, Latheef SK, Chakraborty S, Dhama K, Sridharan TB, Sundaram T, Gulothungan G: Human prostasomes an extracellular vesicle - Biomarkers for male infertility and prostrate cancer: The journey from identification to current knowledge.Int J Biol Macromol 2020, 146:946-958.

2. Levine H, Jørgensen N, Martino-Andrade A, Mendiola J, Weksler-Derri D, Mindlis I, Pinotti R, Swan SH: Temporal trends in sperm count: a systematic review and meta-regression analysis. Hum Reprod Update 2017, 23:646-659.

3. Rabinowitz MJ, Huffman PJ, Haney NM, Kohn TP: Y-Chromosome Microdeletions: A Review of Prevalence, Screening, and Clinical Considerations.Appl Clin Genet 2021, 14:51-59.

4. Bonde JP, Te Velde E: Male factor infertility: Declining sperm counts - the never-ending story.Nat Rev Urol 2017, 14:645-646. 
5. Wdowiak A, Bień A, Iwanowicz-Palus G, Makara-Studzińska M, Bojar I: Impact of emotional disorders on semen quality in men treated for infertility.Neuro Endocrinol Lett 2017, 38:50-58.

6. Coward RM, Stetter C, Kunselman A, Trussell JC, Lindgren MC, Alvero RR, Casson P, Christman GM, Coutifaris C, Diamond MP, et al: Fertility Related Quality of Life, Gonadal Function and Erectile Dysfunction in Male Partners of Couples with Unexplained Infertility.J Urol 2019, 202:379-384.

7. Zou P, Wang X, Sun L, Chen Q, Yang H, Zhou N, Chen H, Zhang G, Ling X, Wang Z, et al: Semen Quality in Chinese College Students: Associations With Depression and Physical Activity in a CrossSectional Study.Psychosom Med 2018, 80:564-572.

8. Mahase E: Covid-19: WHO declares pandemic because of "alarming levels" of spread, severity, and inaction. Bmj 2020, 368:m1036.

9. Nochaiwong S, Ruengorn C, Thavorn K, Hutton B, Awiphan R, Phosuya C, Ruanta Y, Wongpakaran N, Wongpakaran T: Global prevalence of mental health issues among the general population during the coronavirus disease-2019 pandemic: a systematic review and meta-analysis.Sci Rep 2021, 11:10173.

10. Kang L, Li Y, Hu S, Chen M, Yang C, Yang BX, Wang Y, Hu J, Lai J, Ma X, et al: The mental health of medical workers in Wuhan, China dealing with the 2019 novel coronavirus.Lancet Psychiatry 2020, 7:e14.

11. Solomon AW, Kello AB, Bangert M, West SK, Taylor HR, Tekeraoi R, Foster A: The simplified trachoma grading system, amended.Bull World Health Organ 2020, 98:698-705.

12. Mazza MG, De Lorenzo R, Conte C, Poletti S, Vai B, Bollettini I, Melloni EMT, Furlan R, Ciceri F, RovereQuerini P, Benedetti F: Anxiety and depression in COVID-19 survivors: Role of inflammatory and clinical predictors.Brain Behav Immun 2020, 89:594-600.

13. Stein MB: EDITORIAL: COVID-19 and Anxiety and Depression in 2020.Depress Anxiety 2020, 37:302.

14. Wang ZH, Yang HL, Yang YQ, Liu D, Li ZH, Zhang XR, Zhang YJ, Shen D, Chen PL, Song WQ, et al: Prevalence of anxiety and depression symptom, and the demands for psychological knowledge and interventions in college students during COVID-19 epidemic: A large cross-sectional study.J Affect Disord 2020, 275:188-193.

15. Lebel C, MacKinnon A, Bagshawe M, Tomfohr-Madsen L, Giesbrecht G: Elevated depression and anxiety symptoms among pregnant individuals during the COVID-19 pandemic.J Affect Disord 2020, 277:5-13.

16. Tang W, Hu T, Hu B, Jin C, Wang G, Xie C, Chen S, Xu J: Prevalence and correlates of PTSD and depressive symptoms one month after the outbreak of the COVID-19 epidemic in a sample of homequarantined Chinese university students.J Affect Disord 2020, 274:1-7.

17. Wu Y, Zhang C, Liu H, Duan C, Li C, Fan J, Li H, Chen L, Xu H, Li X, et al: Perinatal depressive and anxiety symptoms of pregnant women during the coronavirus disease 2019 outbreak in China.Am J Obstet Gynecol 2020, 223:240.e241-240.e249.

18. Karanikola MNK, Lyberg A, Holm AL, Severinsson E: The Association between Deliberate Self-Harm and School Bullying Victimization and the Mediating Effect of Depressive Symptoms and SelfStigma: A Systematic Review.Biomed Res Int 2018, 2018:4745791. 
19. Kroenke K, Spitzer RL, Williams JB: The PHQ-9: validity of a brief depression severity measure.J Gen Intern Med 2001, 16:606-613.

20. Kroenke K, Stump TE, Chen CX, Kean J, Damush TM, Bair MJ, Krebs EE, Monahan PO: Responsiveness of PROMIS and Patient Health Questionnaire (PHQ) Depression Scales in three clinical trials. Health Qual Life Outcomes 2021, 19:41.

21. Kroenke K, Spitzer RL, Williams JB, Löwe B: The Patient Health Questionnaire Somatic, Anxiety, and Depressive Symptom Scales: a systematic review.Gen Hosp Psychiatry 2010, 32:345-359.

22. Wang W, Bian Q, Zhao Y, Li X, Wang W, Du J, Zhang G, Zhou Q, Zhao M: Reliability and validity of the Chinese version of the Patient Health Questionnaire (PHQ-9) in the general population.Gen Hosp Psychiatry 2014, 36:539-544.

23. Lu JC, Huang YF, Lü NQ: [WHO Laboratory Manual for the Examination and Processing of Human Semen: its applicability to andrology laboratories in China].Zhonghua Nan Ke Xue 2010, 16:867-871.

24. van den Hoven L, Hendriks JC, Verbeet JG, Westphal JR, Wetzels AM: Status of sperm morphology assessment: an evaluation of methodology and clinical value.Fertil Steril 2015, 103:53-58.

25. Cooper TG, Noonan E, von Eckardstein S, Auger J, Baker HW, Behre HM, Haugen TB, Kruger T, Wang C, Mbizvo MT, Vogelsong KM: World Health Organization reference values for human semen characteristics. Hum Reprod Update 2010, 16:231-245.

26. Sharma R, Harlev A, Agarwal A, Esteves SC: Cigarette Smoking and Semen Quality: A New Metaanalysis Examining the Effect of the $\mathbf{2 0 1 0}$ World Health Organization Laboratory Methods for the Examination of Human Semen.Eur Urol 2016, 70:635-645.

27. Johnson SL, Dunleavy J, Gemmell NJ, Nakagawa S: Consistent age-dependent declines in human semen quality: a systematic review and meta-analysis.Ageing Res Rev 2015, 19:22-33.

28. Ma JX, Wang B, Li HS, Jiang XJ, Yu J, Ding CF, Chen WQ: Association between obesity-associated markers and semen quality parameters and serum reproductive hormones in Chinese infertile men.Reprod Biol Endocrinol 2020, 18:95.

29. Cooper TG: Semen quality: variations among fathers and effects of moderate alcohol drinking.Asian J Androl 2015, 17:46-47.

30. Zeynalova N, Schimpf S, Setter C, Yahiaoui-Doktor M, Zeynalova S, Lordick F, Loeffler M, Hinz A: The association between an anxiety disorder and cancer in medical history.J Affect Disord 2019, 246:640-642.

31. Blay RM, Pinamang AD, Sagoe AE, Owusu EDA, Koney NK, Arko-Boham B: Influence of Lifestyle and Environmental Factors on Semen Quality in Ghanaian Men.Int J Reprod Med 2020, 2020:6908458.

32. Ma J, Wu L, Zhou Y, Zhang H, Xiong C, Peng Z, Bao W, Meng T, Liu Y: Association between BMI and semen quality: an observational study of 3966 sperm donors. Hum Reprod 2019, 34:155-162.

33. Kernan WN, Viscoli CM, Brass LM, Broderick JP, Brott T, Feldmann E, Morgenstern LB, Wilterdink JL, Horwitz RI: Phenylpropanolamine and the risk of hemorrhagic stroke. N Engl J Med 2000, 343:18261832. 
34. Jaddoe VW, de Jonge LL, Hofman A, Franco OH, Steegers EA, Gaillard R: First trimester fetal growth restriction and cardiovascular risk factors in school age children: population based cohort study. $B m j$ 2014, 348:g14.

35. Bukowski R, Smith GC, Malone FD, Ball RH, Nyberg DA, Comstock CH, Hankins GD, Berkowitz RL, Gross SJ, Dugoff L, et al: Fetal growth in early pregnancy and risk of delivering low birth weight infant: prospective cohort study.Bmj 2007, 334:836.

36. Bhongade MB, Prasad S, Jiloha RC, Ray PC, Mohapatra S, Koner BC: Effect of psychological stress on fertility hormones and seminal quality in male partners of infertile couples.Andrologia 2015, 47:336-342.

37. Nordkap L, Jensen TK, Hansen $\AA$ M, Lassen TH, Bang AK, Joensen UN, Blomberg Jensen $M$, Skakkebæk NE, Jørgensen N: Psychological stress and testicular function: a cross-sectional study of 1,215 Danish men.Fertil Steril 2016, 105:174-187.e171-172.

38. Zhou T, Zhang W, Chen Q, Li L, Cao H, Xu CL, Chen GH, Sun YH: Effect of varicocelectomy on testis volume and semen parameters in adolescents: a meta-analysis.Asian J Androl 2015, 17:1012-1016.

39. Virtanen HE, Jørgensen N, Toppari J: Semen quality in the 21(st) century.Nat Rev Uro/ 2017, 14:120130.

40. Rahban R, Priskorn L, Senn A, Stettler E, Galli F, Vargas J, Van den Bergh M, Fusconi A, Garlantezec R, Jensen TK, et al: Semen quality of young men in Switzerland: a nationwide cross-sectional population-based study.Andrology 2019, 7:818-826.

41. Mishra P, Negi MPS, Srivastava M, Singh K, Rajender S: Decline in seminal quality in Indian men over the last 37 years. Reprod Biol Endocrinol 2018, 16:103.

42. Li WN, Jia MM, Peng YQ, Ding R, Fan LQ, Liu G: Semen quality pattern and age threshold: a retrospective cross-sectional study of 71,623 infertile men in China, between 2011 and 2017.Reprod Biol Endocrinol 2019, 17:107.

43. Goodyer IM, Herbert J, Tamplin A, Altham PM: Recent life events, cortisol, dehydroepiandrosterone and the onset of major depression in high-risk adolescents.Br J Psychiatry 2000, 177:499-504.

44. Cherian K, Schatzberg AF, Keller J: HPA axis in psychotic major depression and schizophrenia spectrum disorders: Cortisol, clinical symptomatology, and cognition.Schizophr Res 2019, 213:72-79.

45. Schatzberg AF, Keller J, Tennakoon L, Lembke A, Williams G, Kraemer FB, Sarginson JE, Lazzeroni LC, Murphy GM: HPA axis genetic variation, cortisol and psychosis in major depression.Mol Psychiatry 2014, 19:220-227.

46. Jannatifar R, Parivar K, Hayati Roodbari N, Nasr-Esfahani MH: The Effect of N-Acetyl-Cysteine on NRF2 Antioxidant Gene Expression in Asthenoteratozoospermia Men: A Clinical Trial Study.Int J Fertil Steril 2020, 14:171-175.

47. Maresch CC, Stute DC, Alves MG, Oliveira PF, de Kretser DM, Linn T: Diabetes-induced hyperglycemia impairs male reproductive function: a systematic review. Hum Reprod Update 2018, 24:86-105.

\section{Figures}




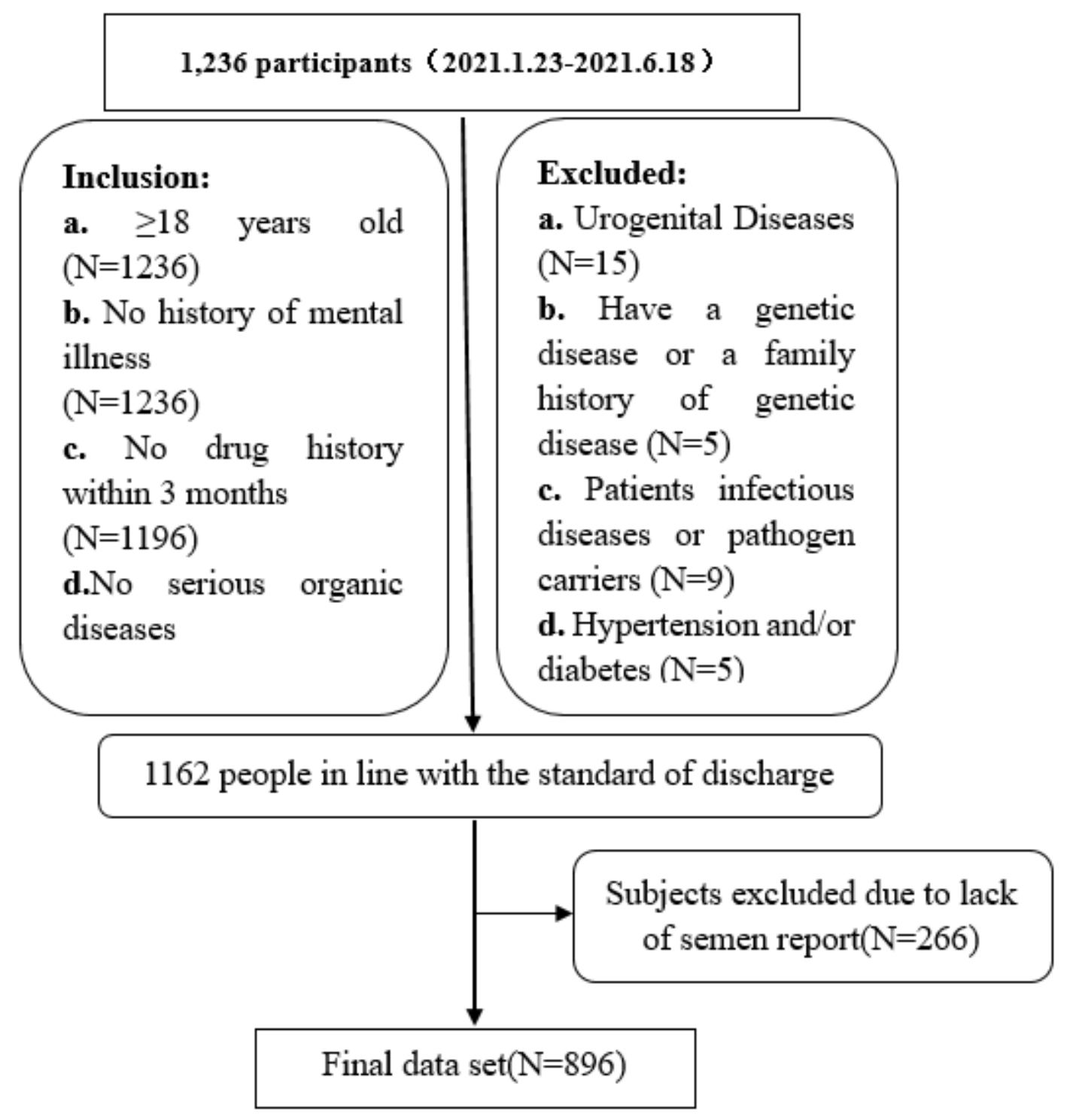

Figure 1

Flowchart showing derivation of study cohort 


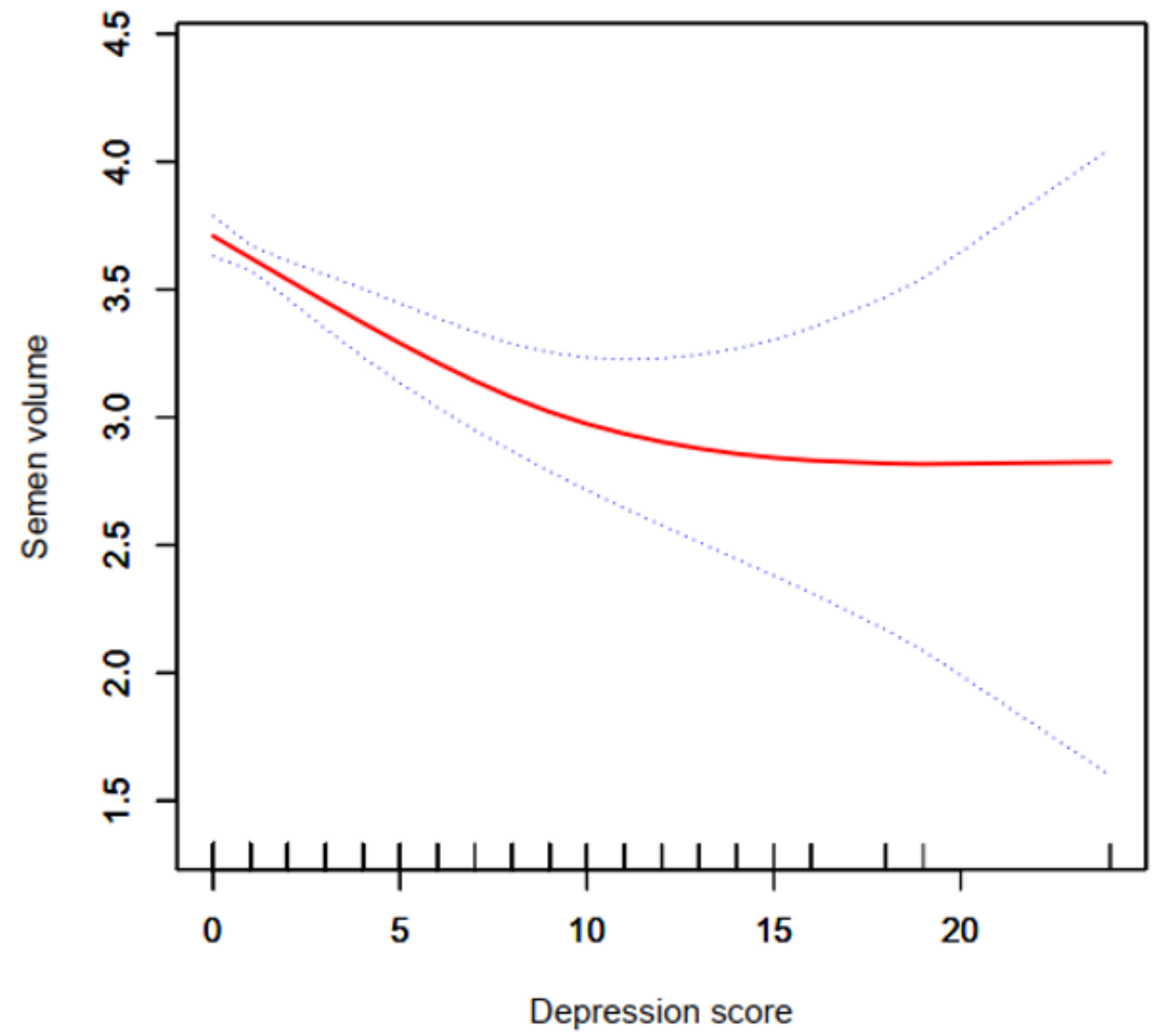

Figure 2

Depression score and semen volume dose-response relationship adjusted for smoking, drinking, BMI, age 


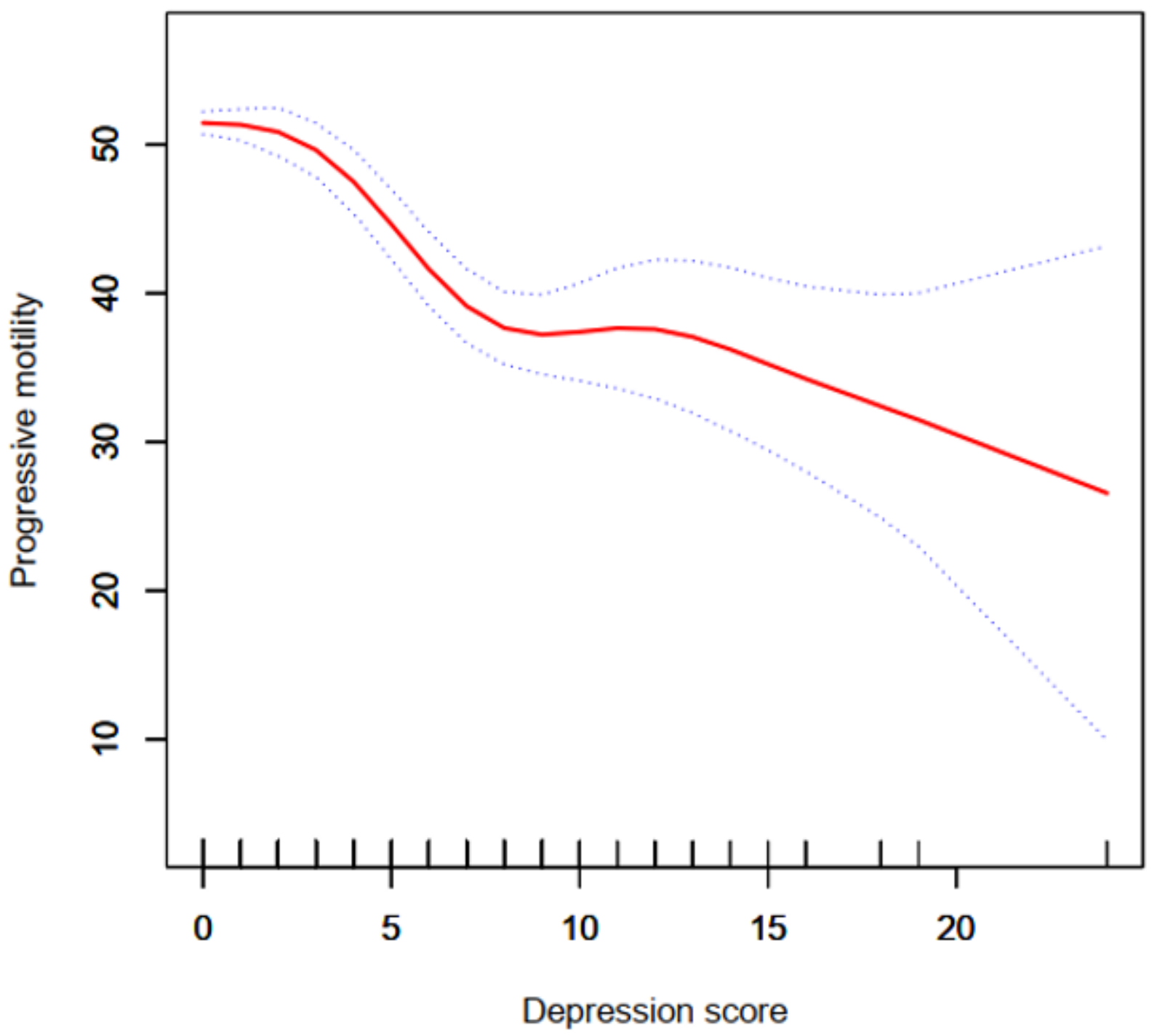

Figure 3

Depression score and progressive motility dose-response relationship adjusted for smoking, drinking, $\mathrm{BMI}$, age

\section{Supplementary Files}

This is a list of supplementary files associated with this preprint. Click to download.

- supplementarymaterial1.docx 